\title{
Comparison of Recovery Time of Propofol and Midazolam with Propofol Alone for Sedation in Endoscopic Retrograde Cholangiopancreatography
}

ASMA SAMREEN ${ }^{1}$, AAMIR WASEEM ${ }^{2}$, MUHAMMAD AZAM ${ }^{3}$, ITRAT HUSSAIN KAZMI ${ }^{4}$, AAMIR BASHIR ${ }^{5}$, SARMAD MASUD 6

${ }^{1}$ Senior Registrar Anesthesia, Shalamar Medical \& Dental College, Lahore

${ }^{2}$ Assistant Professor Anesthesia, Shalamar Medical \& Dental College, Lahore

${ }^{3}$ Associate Professor Anesthesia, Services Institute of Medical Sciences, Lahore

${ }^{4}$ Assistant Professor Anesthesia, Shalamar Medical \& Dental College, Lahore

${ }^{5}$ Assistant Professor Anesthesia, Shalamar Medical \& Dental College, Lahore

${ }^{6}$ Professor of Anesthesia, Sharif Medical \& Dental College, Lahore

Correspondence to Dr. Asma Samreen, Email:asmajee_khan@hotmail.com, Phone: +92 3336913050

\begin{abstract}
Background: Procedural sedation is required for multiple short duration procedures outside of the operating rooms especially in radiology and endoscopy suites. Intravenous anesthetic agent with rapid recovery profile is desirable in such circumstances. This study aims to compare two regimens of intravenous anesthetic agents.

Aim: To compare the mean recovery time of propofol and midazolam with propofol alone for sedation in endoscopic retrograde cholangiopancreatography.

Study Design: Randomized controlled trial.

Settings: Department of Anesthesia, Shalamar Hospital, Lahore.

Study Duration: June 2017 to December 2017.

Methods: A total of 70 adult patients aged 20-60 years undergoing ERCP under sedation were included. Patients were given a combination of propofol and midazolam in group A while propofol alone was given in group B. After procedure, pts were transferred to recovery room and were followed for assessment of recovery time. Data were analyzed in SPSS vr 21, Independent t-test was applied \& p-value $\leq 0.05$ was considered statistically significant.

Results: Significant difference was found in mean recovery time amongst both the groups. Mean recovery time in Group A (propofol and midazolam) was $19.29 \pm 4.50$ minutes while in Group B (propofol alone) was $26.66 \pm 3.70$ minutes showing statistically significant result with $p$-value $=0.0001$.

Conclusion: We conclude that mean recovery time with propofol plus midazolam is shorter as compared to propofol alone for sedation in ERCP.

Keywords: Propofol, midazolam, sedation outside operation theatre.
\end{abstract}

\section{INTRODUCTION}

Monitored anaesthesia care for endoscopic procedures has been routinely practiced throughout the modern world. In addition to that, conscious sedation practices is increasingly being used for diagnostic and therapeutic procedures outside operation theatre including endoscopic procedures $^{1,2}$. Data also suggests that physician directed use of propofol sedation is increasing with due course of time ${ }^{3}$.

Various intravenous anesthetics medications including midazolam, propofol, thiopental, ketamine, and natural and synthetic opioids are in use. The properties of an ideal intravenous anesthetic medication include a rapid onset and fast recovery time as well as minimal side effects and hangover later on. It also includes minimal effects on hemodynamics to make it useful for hemodynamically unstable and frail patients. Considering all these properties, currently propofol is commonly used intravenous anesthetic agent for induction of general anesthesia. Pharmacologic properties of propofol includes being highly lipophilic and rapid redistribution, that makes it fast onset of action and rapid recovery respectively 4 .

Received on 03-01-2021

Accepted on 23-05-2021
Endoscopic procedures are at times, uncomfortable and painful for the patients. Therefore, sedation helps the patients to tolerate the procedure well and improving their satisfaction after a diagnostic or therapeutic endoscopic procedure. In addition, a trend can be observed towards an increasing use of propofol as the preferred sedative drug ${ }^{1}$. A randomized trial study comparing propofol plus midazolam and propofol alone reported that the mean recovery time was shortened in propofol plus midazolam group (19 $\pm 7 \mathrm{~min}$ ) as compared to propofol alone group (25 $\pm 8 \mathrm{~min})$. This difference was significant $(p<005)^{5}$. In another study, the authors found that recovery time significantly shorter in the group of patients sedated with propofol alone $(12 \pm 7)$ minutes as compared to the group that received additional midazolam $(44 \pm 13)$ minutes $(p=0.0001)^{6}$.

However, in another study comparing combination of propofol and midazolam versus propofol alone for sedation during colonoscopy. Profofol alone was found with longer recovery time as compared to combination therapy. Higher doses of profofol required to achieve deeper level of sedation would have been the possible reason of longer recovery time when compared with combination therapy $(p<0.001)^{7,8}$. It would be worthwhile to further explore the use of these drugs for sedation during gastrointestinal endoscopy. The rationale for this study was to seek further 
clarification on this issue and add to the existing evidence. This study may help to improve our current practice and may also help to achieve more patient's satisfaction by shorter recovery time.

The objective of the study was to compare the mean recovery time of propofol and midazolam versus propofol alone for sedation in endoscopic retrograde cholangiopancreatography.

Recovery time: It was defined as duration of time in minutes from withdrawal of endoscope to a state when the patient was fully awake and conversant ${ }^{6}$. Recovery time was assessed by conversation with patient at1-minute interval.

\section{METHODOLOGY}

This randomized controlled trial was conducted in the Department of Anesthesia, Shalamar Hospital, Lahore from June 2017 to December 2017. The sample size was calculated as total of 70 cases with 35 each in group A \& B, by $5 \%$ level of significance, $80 \%$ power of test and mean recovery time with propofol plus midazolam $19 \pm 7 \mathrm{~min}^{5}$ whilemean recovery time with propofol $25 \pm 8 \mathrm{~min}^{5}$. Sampling technique was non-probability, consecutive sampling. We included patients undergoing ERCP under sedation of aged 20-60 years, with ASA physical status I \& II and of either gender. We excluded patients with uncontrolled hypertension, uncontrolled diabetes mellitus, morbid obesity, patients undergoing emergency procedure, known habitual use of sedatives and allergic to anesthetic medications to be used in study.

Data collection procedure: After approval from institutional review board and informed written consent, a total of 70 patients who fulfilled the selection criteria and planned for ERCP under sedation were included in study. Demographic data including name, age, gender and BMI were recorded. Patients were randomly divided in two groups by using lottery method. Group A patients were given a combination of propofol and midazolam (propofol dose: $25-100 \mathrm{mcg} / \mathrm{kg} / \mathrm{min}$ \& midazolam dose: $0.01-$ $0.1 \mathrm{mg} / \mathrm{kg}$ ). Propofol alone was given in group B patients (propofol dose: $25-100 \mathrm{mcg} / \mathrm{kg} / \mathrm{min}$ ). Standard anesthetic monitoring and oxygen via facemask were implied to all patients. A single gastroenterology team performed ERCP. The researcher administered the anaesthetic agents. After procedure, patients were transferred to the recovery room and were followed up for assessment of recovery time. All this information was recorded on predesigned proforma.

Statistical analysis: Data were entered and analyzed in SPSS version 21. Quantitative variables like age, BMI and recovery time were measured as mean and standard deviation while qualitative variables like gender were measured as frequency and percentages. Independent ttest was applied to compare mean recovery time between two groups. $P$ value $\leq 0.05$ was considered as significant. Effect modifiers like age gender and BMI were controlled by stratification.

\section{RESULTS}

A total of 70 patients were included in study aged 20 to 60 years with mean age of $26.04 \pm 11.17$ years. The mean age of patients in group A was 35.29 \pm 11.14 years and in-group $B$ was $36.80 \pm 11.32$ years. Out of 70 patients $49(70 \%)$ were males and $21(30 \%)$ were females. Overall, mean BMI was $29.39 \pm 3.21 \mathrm{~kg} / \mathrm{m}^{2}$ while the mean BMl in group A was $29.31 \pm 3.11 \mathrm{~kg} / \mathrm{m}^{2}$ and in group $B$ was $29.46 \pm 3.35 \mathrm{~kg} / \mathrm{m}^{2}$. Mean recovery time in Group A (propofol and midazolam) was $19.29 \pm 4.50$ minutes while in Group B (propofol alone) was $26.66 \pm 3.70$ minutes ( $p$-value $=0.0001$ ) (Figure 1$)$.

Stratification of mean recovery time with respect to age groups, gender and BMI also showed significant result as shown in tables I, II and III below respectively.

Figure I: Comparison of the mean recovery time with propofol plus midazolam versus propofol alone for sedation in ERCP.

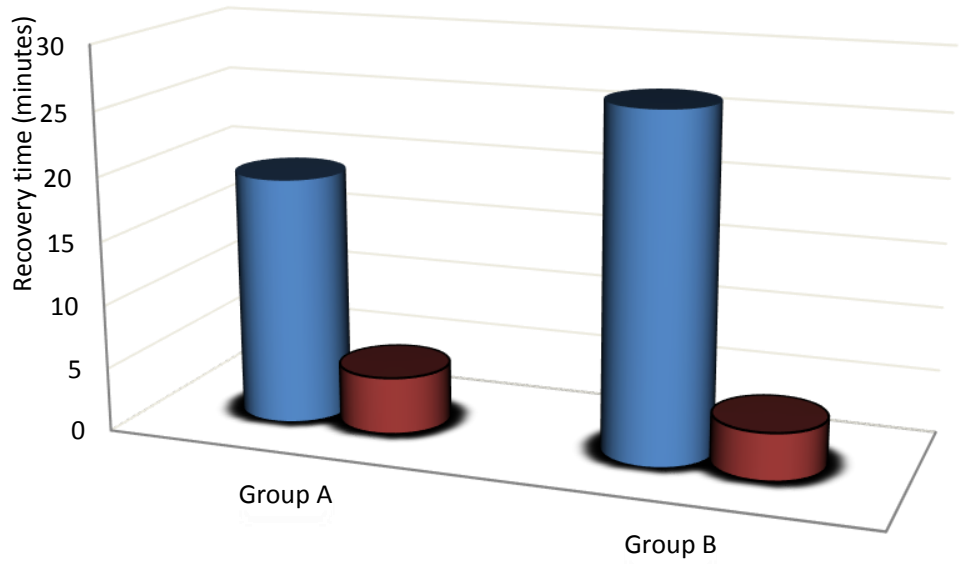

\begin{tabular}{|l|c|c|}
\cline { 2 - 3 } \multicolumn{1}{c|}{} & Group A & Group B \\
\hline Mean & 19.29 & 26.66 \\
\hline Standard Deviation & 4.5 & 3.7 \\
\hline
\end{tabular}


Table I: Stratification of mean recovery time with respect to age groups.

\begin{tabular}{|l|l|l|l|l|l|}
\hline \multirow{3}{*}{ Age of patients (years) } & \multicolumn{2}{|c|}{ Group A (n=35) } & \multicolumn{2}{c|}{ Group B (n=35) } & \multirow{2}{*}{ P-value } \\
\cline { 2 - 5 } & \multicolumn{2}{|c|}{ Recovery time (minutes) } & \multicolumn{2}{c|}{ Recovery time (minutes) } & \\
\cline { 2 - 6 } & Mean & SD & Mean & 3.25 & 0.0001 \\
\hline $20-40$ & 19.41 & 4.26 & 27.42 & 4.09 & 0.0008 \\
\hline $41-60$ & 19.08 & 5.04 & 25.75 & \\
\hline
\end{tabular}

Table II: Stratification of mean recovery time with respect to gender.

\begin{tabular}{|l|l|l|l|l|l|}
\hline \multirow{3}{*}{ Gender } & \multicolumn{2}{|c|}{ Group A (n=35) } & \multicolumn{2}{c|}{ Group B (n=35) } & \multirow{2}{*}{ P-value } \\
\cline { 2 - 5 } & Recovery time (minutes) & \multicolumn{2}{c|}{ Recovery time (minutes) } & \\
\cline { 2 - 5 } & Mean & SD & Mean & SD & \\
\hline Male & 18.80 & 4.79 & 26.29 & 3.93 & 0.0001 \\
\hline Female & 20.50 & 3.60 & 27.45 & 3.17 & 0.0002 \\
\hline
\end{tabular}

Table III: Stratification of mean recovery time with respect to BMI.

\begin{tabular}{|c|c|c|c|c|c|}
\hline \multirow{3}{*}{ BMI $\left(\mathbf{k g} / \mathrm{m}^{2}\right)$} & \multirow{2}{*}{\multicolumn{2}{|c|}{$\begin{array}{c}\text { Group A ( } n=35) \\
\text { Recovery time (minutes) }\end{array}$}} & \multirow{2}{*}{\multicolumn{2}{|c|}{$\begin{array}{c}\text { Group B ( } n=35) \\
\text { Recovery time (minutes) }\end{array}$}} & \multirow{3}{*}{ P-value } \\
\hline & & & & & \\
\hline & Mean & SD & Mean & SD & \\
\hline$\leq 27$ & 19.46 & 6.04 & 27.21 & 3.45 & 0.0007 \\
\hline$>27$ & 19.18 & 3.45 & 26.29 & 3.90 & 0.0001 \\
\hline
\end{tabular}

\section{DISCUSSION}

Invasive diagnostic and therapeutic endoscopic procedures include Endoscopic retrograde cholangiopancreatography (ERCP) and various others. These are quite bothersome and uncomfortable in considerable number of patients requiring adequate analgesia and procedural sedation. ERCP is usually performed for the diagnosis and treatment of pancreato-biliary disorders. It is frequently prolonged and potentially uncomfortable for the patients and therefore requires adequate patient sedation ${ }^{9}$.

Multiple anaesthetic medications are in use for procedural sedation. Commonly used and easily available benzodiazepine class medicine "midazolam" works as sedative, anxiolytic, hypnotic and provides retrograde amnesia ${ }^{10}$. Midazolam is short acting and fast recovery time. Even we can use its antidote flumazenil in cases of midazolam over dosage ${ }^{11}$. Propofol is more widely used intravenous anesthetic agent considering its rapid onset and rapid recovery ${ }^{12}$. It has a shorter half-life than midazolam and a quicker recovery time. However, propofol use can lead to serious cardiorespiratory complications in certain patients when compared with midazolam. These complications include, injection site pain, hypotension, apnea and there is no specific antagonist for propofol ${ }^{13}$. Profofol had been proven superior to midazolam for procedural sedation during ERCP in few studies ${ }^{14,15}$. However there is evidence that the combined use of propofol and midazolam for sedation has some benefits and no safety concerns, compared to using either drug alone ${ }^{16-18}$. Our study was conducted to compare the mean recovery time with propofol and midazolam versus propofol alone for sedation in endoscopic retrograde cholangiopancreatography. Mean recovery time in Group A (propofol plus midazolam) was $19.29 \pm 4.50$ minutes while in Group B (propofol alone) was $26.66 \pm 3.70$ minutes ( $p$ value $=0.0001)$. Our results are quite comparable to a previously conducted randomized trial comparing propofol and midazolam with propofol alone as for example, Seifert et al reported that the mean recovery time was shortened in propofol and midazolam group (19 $\pm 7 \mathrm{~min})$ as compared to propofol alone group $(25 \pm 8 \mathrm{~min})^{5}$. Vargo et al found that the mean time to sedation was 8 minutes in the group administered midazolam and meperidine and 3.9 minutes in a group administered propofol alone ${ }^{19}$. Considering total dose of medications used, a study that compared propofol alone with propofol and oral midazolam found that the total propofol dose required for ERCP was much smaller in the propofol with oral midazolam group $(330.7 \mathrm{mg})$ than the propofol alone group $(512 \mathrm{mg})^{20}$. Combined use of midazolam and propofol is a more effective sedation method for ERCP compared to midazolam alone. The combined use resulted in a shorter time to initial effective sedation and a quicker recovery. There were no significant differences between the two regimens with respect to the rate of adverse events. Patient cooperation rated as excellent by the endoscopist was greater in the combination group ${ }^{21}$.

Combination therapy of midazolam and profofol has been documented having prolonged recovery. This might be due to pharmacodynamic interaction of midazolam during prolonged propofol infusion resulting in slowing of profol distribution and clearance of midazolam when used with propofol infusion with an overall effect of prolonged recovery from combination therapy ${ }^{22}$. Comparing propofol and midazolam has proven faster recovery in propofol groups. However, recovery occurred ater in the intravenous propofol plus oral midazolam group than in the propofol alone group ${ }^{18}$. In a study that used the modified Aldrete scoring system, the score was checked initially 15 minutes after the procedure (i.e., the scores were checked at 15, 30,45 , and 60 minutes); each result was significantly faster in the propofol group ${ }^{23}$. Patient cooperation and satisfaction was found superior in a study using propofol with oral midazolam as the premedication as compared to propofol alone group. ${ }^{16}$ Other sedative medications like meperidine has shown controversial results when used alone or in combination with midazolam or propofol for sedation in endoscopic procedures ${ }^{24}$.

Geriatric patients are much sensitive to sedative medications due to frailty, multiple comorbidities and altered pharmacologic response to sedative medications. However, when used in titrated doses considering age of the patients, propofol alone or in combination with midazolam has not been associated with significant complications and were comparable results in recovery 
time during endoscopic procedures ${ }^{25}$.

The combination of propofol and midazolam may have synergistic effectsand poses advantage over the use of propofol alone. This can result in significantly reduced dose requirement of propofol when used in combination with midazolam as shown by an observational study on more than 200 patients for sedation during endoscopy ${ }^{26}$.

\section{CONCLUSION}

We concluded that mean recovery time with propofol and midazolam is shorter as compared to propofol alone for sedation in ERCP. We recommend that midazolam should be used in combination with propofol for sedation during ERCP in our general practice to have a shorter recovery time which will make our patients more comfortable during procedure.

Limitations of study: This study was conducted for procedures of ERCP only. However, further study can be conducted with larger sample size and more procedures requiring procedural sedation.

Acknowledgements: Anesthesia and gastroenterology department Shalamar Hospital Lahore

Conflict of interest: Nil

Funding resources: Nil

Contribution of authors: AS: Designing manuscript, data collection, AW: Designing manuscript and data interpretation, MA: Designing manuscript and data interpretation, IHK: Data collection and interpretation, AB: Data interpretation, statistical analysis, SM: Supervision, statistical analysis

\section{REFERENCES}

1. Heuss L, Froehlich F, Beglinger C. Nonanesthesiologst-administered propofol sedation: from the exception to standard practice. Sedation and monitoring trends over 20 years. Endoscopy. 2012; 44:504-11.

2. Triantafillidis JK, Merikas E, Nikolakis D, Papalois AE. Sedation in gastrointestinal endoscopy: current issues. World J Gastroenterol. 2013; 19:463-81.

3. Dumonceau JM, Riphaus A, Aparicio J, Beilenhoff U, Knape J, Ortmann $\mathrm{M}$, et al. European society of gastrointestinal endoscopy, European Society of Gastroenterology and Endoscopy Nurses and associates and the European Society of Anesthesiology guidelines: non-anesthesiologist administration of propofol for Gl endoscopy. Endoscopy. 2010; 42:960-74.

4. Mannarino R, Luna SP, Monterio ER, Beier SI, Castro VB. Minimum infusion rate and hemodynamic effects of propofol, propofol-lidocaineketamine in dogs. Vet Anesth analg. 2012; 39:160-73.

5. Seifert H, Schmitt T, Gultekin T, Caspary W, Wehrmann T. Sedation with propofol plus midazolam versus propofol alone for interventional endoscopic procedures: a prospective randomized study. Alimentary Pharmacol Therapeutic. 2000; 14:1207-14.

6. Khan HA, Umar M, Tul Bushra H, Nisar G, Zia S. Propofol plus midazolam versus propofol alone sedation in therapeutic endoscopic retrograde cholangiopancreatography (ERCP). J Rawalpindi Med Coll. 2013; 17:163-6.

7. Lee TH, Lee CK, Park SH, Lee SH. Balanced propofol sedation versus propofol monosedation in therapeutic pancreaticobiliary endoscopic procedures. Dig Dis Sci. 2012; 57:2113-21.
8. VanNatta ME, Rex DK. Propofol alone titrated to deep sedation versus propofol in combination with opioids and/or benzodiazepines and titrated to moderate sedation for colonoscopy. Am J Gastroenterol. 2006; 101:2209-17.

9. Garewal D, Waikar P. Propofol sedation for ERCP procedures: a dilemna? Observations from an anesthesia perspective. Diagn Ther Endosc. 2012; 2012:639190.

10. Walser A, Zenchoff G, Fryer RI. Quinazolines and 1,4benzodiazepines. 75. 7-Hydroxyaminobenzodiazepines and derivatives. J Med Chem. 1976; 19:1378-81.

11. Garewal D, Powell S, Milan SJ, Nordmeyer J, Waikar P. Sedative techniques for endoscopic retrograde cholangiopancreatography. Cochrane Database Syst Rev. 2012; 6:CD007274.

12. Sear JW, Uppington J, Kay NH. Haematological and biochemical changes during anaesthesia with propofol ('Diprivan') Postgrad Med J. 1985; 61:165-68.

13. Heuss LT, Schnieper P, Drewe J, Pflimlin E, Beglinger C. Conscious sedation with propofol in elderly patients: a prospective evaluation. Aliment Pharmacol Ther. 2003; 17:1493-1501.

14. Riphaus A, Stergiou N, Wehrmann T. Sedation with propofol for routine ERCP in high-risk octogenarians: a randomized, controlled study. Am J Gastroenterol. 2005; 100:1957-63.

15. Paspatis GA, Charoniti I, Manolaraki M, et al. Synergistic sedation with oral midazolam as a premedication and intravenous propofol versus intravenous propofol alone in upper gastrointestinal endoscopies in children: a prospective, randomized study. J Pediatr Gastroenterol Nutr. 2006; 43:195-99.

16. Paspatis GA, Manolaraki M, Xirouchakis G, Papanikolaou N, Chlouverakis G, Gritzali A. Synergistic sedation with midazolam and propofol versus midazolam and pethidine in colonoscopies: a prospective, randomized study. Am J Gastroenterol. 2002; 97:196367.

17. Paspatis GA, Manolaraki MM, Vardas E, Theodoropoulou A Chlouverakis G. Deep sedation for endoscopic retrograde cholangiopancreatography: intravenous propofol alone versus intravenous propofol with oral midazolam premedication. Endoscopy. 2008; 40:308-13.

18. Reimann FM, Samson U, Derad I, Fuchs M, Schiefer B, Stange EF Synergistic sedation with low-dose midazolam and propofol for colonoscopies. Endoscopy. 2000; 32:239-44.

19. Vargo JJ, Zuccaro G, Jr, Dumot JA, et al. Gastroenterologistadministered propofol versus meperidine and midazolam for advanced upper endoscopy: a prospective, randomized trial. Gastroenterology. 2002;123:8-16.

20. Kim YS, Kim MH, Jeong SU, Lee BU, Lee SS, Park DH, et al Comparison between Midazolam Used Alone and in Combination with Propofol for Sedation during Endoscopic Retrograde Cholangiopancreatography. Clin Endosc. 2014; 47: 94-100.

21. Lichtenbelt BJ, Olofsen E, Dahan A, van Kleef JW, Struys MM, Vuyk J. Propofol reduces the distribution and clearance of midazolam. Anesth Analg 2010; 110:1597-1606.

22. Kongkam P, Rerknimitr R, Punyathavorn S, et al. Propofol infusion versus intermittent meperidine and midazolam injection for conscious sedation in ERCP. J Gastrointestin Liver Dis 2008; 17:291-97.

23. Schilling D, Rosenbaum A, Schweizer S, Richter H, Rumstadt B Sedation with propofol for interventional endoscopy by trained nurses in high-risk octogenarians: a prospective, randomized, controlled study. Endoscopy 2009; 41:295-98

24. Adachi $\mathrm{YU}$, Watanabe $\mathrm{K}$, Higuchi $\mathrm{H}$, Satoh $\mathrm{T}$ : $\mathrm{A}$ small dose of midazolam decreases the time to achieve hypnosis without delaying emergence during short-term propofol anesthesia. J Clin Anesth 2001; 13:277-80.

25. Kerker A, Hardt C, Schlief HE, Dumoulin FL. Combined sedation with midazolam/propofol for gastrointestinal endoscopy in elderly patients. BMC Gastroenterology 2010; 10:11.

26. Cordruwisch $W$, Doroschko $M$, Wurbs $D$ : Deep sedation in gastrointestinal endoscopic interventions: safety and reliability of a combination of midazolam and propofol. Dtsch Med Wochenschr 2000; 125:619-22. 